\title{
The Examination of Brucella Cultures for Lysis by Phage
}

\author{
By W. J. B. MORGAN \\ Ministry of Agriculture, Fisheries and Food, Central Veterinary Laboratory, \\ New Haw, Weybridge, Surrey
}

(Received 19 June 1962)

SUMMARY

\begin{abstract}
A total of 3919 brucella cultures was examined for lysis by five brucella phages, using a routine test dilution (R.T.D.) and 10,000 $\times$ R.T.D. All cultures of Brucella abortus examined were lysed by all five phages at both dilutions. In addition, all cultures with the oxidative metabolic pattern characteristic of $\boldsymbol{B}$. abortus, irrespective of their properties as determined by conventional typing methods, were lysed by both phage dilutions. Cultures of $B$. suis were not lysed by phages at R.T.D. but all showed lysis by phages at $10,000 \times$ R.T.D. Cultures of $B$. melitensis and those with the oxidative metabolic pattern characteristic of $B$. melitensis, irrespective of their properties as determined by conventional typing methods, were not lysed by phages at either dilution. All five phages used (Tb, 10/I, 24/II, $212 / \mathrm{XV}$ and 371/XXIX) displayed an identical host range; this was confirmed by neutralization tests with antiphage sera.
\end{abstract}

\section{INTRODUCTION}

In a previous publication (Morgan, Kay \& Bradley, 1960) it was shown that a brucella phage obtained from the U.S.S.R. (Tbilisi or Tb phage) when used at a routine test dilution was able to lyse cultures of Brucella abortus but not of B. suis. Some of the $\boldsymbol{B}$. melitensis cultures examined were lysed but others were not. Cultures of $B$. melitensis isolated abroad (U.S.A., Malta) were not lysed whilst cultures with the biochemical and serological properties of $B$. melitensis isolated from cattle in Great Britain were lysed. It was therefore possible to distinguish between these British cultures and the Mediterranean strains. Four new phages isolated in Poland (Parnas, 1961) have now become available to us. The purpose of the present paper is to report on the examination of these phages when tested with a larger collection of brucella cultures.

\section{METHODS}

Phages. In addition to the Soviet phage $\mathrm{Tb}$, four other phages received from Professor J. Parnas (Lublin, Poland), were used; phages 10/I, 24/II and 371/XXIX had been isolated from carrier cultures of Brucella abortus and phage $212 / \mathrm{XV}$ from a culture of $B$. suis. Phage stocks were prepared by the double agar layer technique (Adams, 1959) with a suspension of organisms from a $24 \mathrm{hr}$. culture of B. abortus 544 (FAO/WHO reference strain) as propagating culture. The phages were suspended in phosphate buffer ( $\mathrm{pH} \mathrm{7 \cdot 2)}$ containing albumin (Fildes \& Kay, 1955), the suspension centrifuged and filtered through Oxoid millipore $(0 \cdot 8 \mu$ diam.) filters and stored 
at $4^{\circ}$. All the phages were used at a routine test dilution (R.T.D.) prepared in phosphate buffer containing albumin with $B$. abortus 544 as the indicating culture. The number of plaque-forming particles $(\mathrm{pfp}) / \mathrm{ml}$. in these preparations was assayed by the method of Adams (1959) with B. abortus 544. Counts were made after $48 \mathrm{hr}$. of incubation at $37^{\circ}$ in air containing $10 \%(\mathrm{v} / \mathrm{v})$ added $\mathrm{CO}_{2}$.

Partial purification of phage $\mathrm{Tb}$ was made by alternate low- and high-speed centrifugation. Phage was centrifuged at $100,000 \mathrm{~g}$ in a Spinco centrifuge and resuspended, after two such centrifugations, in albumin buffer.

An antiserum against phage $\mathrm{Tb}$ was prepared in rabbits by using as antigen a crude preparation containing $2.5 \times 10^{10} \mathrm{pfp} / \mathrm{ml}$. Four injections were given every other day, and a week after the last injection two more were given after an interval of 2 days. Blood was collected 10 days after the last injection and the sera Seitzfiltered and stored at $4^{\circ}$. Antisera were also prepared in rabbits against the partially purified phage $\mathbf{T b}$. Neutralization tests for assessing the $K$ values were made by the method of Adams (1959).

Brucella cultures. Cultures recently isolated at this laboratory or sent here from various parts of Great Britain for routine typing constituted the majority of the cultures studied. Tests were made as soon as possible after isolation. Cultures received from other parts of the world were also studied. The type and countries of origin of these cultures are given later in Tables 1 and 4. All cultures were typed by conventional methods (as recommended by the World Health Organization Expert Committee on Brucellosis; Report, 1953); details of the technique and media have already been published (Morgan, 1961).

Media. Serum glucose agar (Morgan, 1960) was used for the growth of cultures and as the basal medium for the propagation and plaque-counting of phage. For the double agar layer technique, the top layer consisted of nutrient agar $+0.5 \%$ $(w / v)$ glucose and $0.7 \%(w / v)$ agar.

For routine typing, growth from $48 \mathrm{hr}$. slopes was suspended in buffered saline (pH 6.4) and a loopful streaked across well-dried serum glucose agar plates. When the five phages were used, three cultures were streaked; plates were dried with the lid partly open for $1 \mathrm{hr}$. at $37^{\circ}$. One drop (0.02 ml.) of each phage suspension at its routine test dilution (R.T.D.) was spotted on the cultures, allowed to dry and the plates incubated for $48 \mathrm{hr}$. in air $+10 \%(\mathrm{v} / \mathrm{v}) \mathrm{CO}_{2}$.

\section{RESULTS}

Phage preparations containing between 2 and $6 \times 10^{11} \mathrm{pfp} / \mathrm{ml}$. were obtained. R.T.D. preparations contained approximately $1 \times 10^{7} \mathrm{pfp} / \mathrm{ml}$. Plaques were not observed when Brucella suis 1330 or $B$. melitensis $16 \mathrm{M}$ were used as lawns; but lysis of $B$. suis though not of $B$. melitensis occurred at the highest dilutions of phage $\left(10^{-1}\right.$ and $10^{-2}$ with high titre stocks).

In Table 1 are given the results of testing with phage, at a routine test dilution, 3919 brucella cultures. Of 3775 cultures isolated in Britain, representing Brucella abortus type I, $B$. abortus type II (dye-sensitive), the variety which is $B$. abortus biochemically and culturally but melitensis serologically and the variety isolated in Great Britain from cattle which has the biochemical, cultural and serological properties of $B$. melitensis, 3736 cultures $(98 \cdot 8 \%)$ were lysed by all the phages used. 
Many of the cultures that were not lysed were rough; the remainder had been disposed of before tests for roughness were made.

Of 144 cultures received from abroad, all 23 strains of Brucella abortus III (thionin-resistant) were lysed and none of 22 cultures of $B$. suis. Fifteen of 37 cultures of $\boldsymbol{B}$. melitensis were lysed by phage, thus resembling these cultures with

Table 1. The lytic effect of brucella phage at its routine test dilution (R.T.D.) on 3919 brucella cultures

\begin{tabular}{|c|c|c|c|}
\hline \multicolumn{4}{|c|}{ No. of cultures } \\
\hline Species or type & Examined & Lysed & Remarks \\
\hline B. abortus type I and type II & $\mathbf{3 4 5 4}$ & $\mathbf{3 4 2 3}$ & Britain \\
\hline B. abortus type III (thionin-resistant) & 23 & 23 & Germany, Uganda and Turkey \\
\hline $\begin{array}{l}\text { B. abortus type III, but agglutinating } \\
\text { in both monospecific sera }\end{array}$ & 4 & 4 & Turkey \\
\hline $\begin{array}{l}\text { Biochemically } B \text {. abortus/serologically } \\
\text { B. melitensis }\end{array}$ & 65 & 65 & $\begin{array}{l}\text { Includes } 3 \text { cultures that were } \\
\text { dyesensitive/serologically } B . \\
\text { melitensis (Britain) }\end{array}$ \\
\hline $\begin{array}{l}\text { Biochemically } B \text {. melitensis/serolo- } \\
\text { gically } B \text {. abortus }\end{array}$ & 13 & 7 & $\begin{array}{l}4 \text { (Turkey), } 1 \text { (Germany) and } 1 \\
\text { (Khartoum) lysed. } 7 \text { (Turkey) } \\
\text { not lysed }\end{array}$ \\
\hline $\begin{array}{l}\text { B. melitensis isolated from cattle in } \\
\text { Britain }\end{array}$ & $\mathbf{2 5 6}$ & $\mathbf{2 4 8}$ & $\begin{array}{l}\text { Britain. The } 8 \text { not lysed were } \\
\text { rough }\end{array}$ \\
\hline B. melitensis (foreign) & 37 & 15 & $\begin{array}{l}14 \text { (Germany), } 1 \text { (Uganda) lysed. } \\
3 \text { (Africa), } 1 \text { (Mexico), } 1 \text { (U.S.A.), } \\
15 \text { (Germany), } 2 \text { (Malta) not } \\
\text { lysed }\end{array}$ \\
\hline $\begin{array}{l}\text { B. melitensis (foreign), but aggluti- } \\
\text { nating in both monospecific sera }\end{array}$ & 45 & 6 & $\begin{array}{l}5 \text { (Uganda), } 1 \text { (Turkey) lysed. } \\
22 \text { (Germany), } 9 \text { (Italy), and } 8 \\
\text { (Turkey) not lysed }\end{array}$ \\
\hline $\begin{array}{l}\text { B. suis type I (4 cultures), B. suis } \\
\text { type II (16 cultures), B. suis type III } \\
\text { ( } 2 \text { cultures) }\end{array}$ & 22 & $\mathbf{0}$ & $\begin{array}{l}\text { Denmark, U.S.A., Switzerland, } \\
\text { Germany and Singapore }\end{array}$ \\
\hline
\end{tabular}

the biochemical and serological properties of $B$. melitensis isolated from cattle in this country. Six cultures that were culturally and biochemically $\boldsymbol{B}$. melitensis but were $B$. abortus serologically were lysed by phage, as also were six cultures that were B. melitensis but which agglutinated in both 'abortus' and 'melitensis' monospecific sera.

In every case a culture was either lysed by all five phage preparations or by none; in no case was a culture lysed by one or two phages and not by the others.

The effect of using phage at R.T.D. and at 10,000 $\times$ R.T.D. was examined on a small number of cultures of each of the three main species; the results are in Table 2. Strains of Brucella abortus were lysed by both dilutions, $\boldsymbol{B}$. melitensis by neither; the strains of $B$. suis showed complete lysis with $10,000 \times$ R.T.D. but no lysis with R.T.D. With these $B$. abortus strains, resistant colonies developed in the area of lysis on incubation for four days but resistant colonies did not develop with $B$. suis strains.

To determine whether this apparent lysis of Brucella suis was caused by phage or by some toxic factor(s) present in the lysate, phage $\mathbf{T b}$ was partially purified by differential centrifugation. The results (Table 3 ) show that the partially purified 
phage containing $6.5 \times 10^{11} \mathrm{pfp} / \mathrm{ml}$. caused lysis of $B$. abortus and $B$. suis but not of $B$. melitensis. At the R.T.D., only $B$. abortus cultures were lysed. The supernatant fluid obtained after high-speed centrifugation caused no lysis of $B$. suis nor $B$. melitensis but caused lysis of $B$. abortus because of the presence of undeposited phage $\left(45 \times 10^{8} \mathrm{pfp} / \mathrm{ml}\right.$.). Attempts to propagate phage $\mathbf{T b}$ with $B$. suis as propagating culture (in solid and liquid media) were unsuccessful, the filtrate either gave no lysis of $\boldsymbol{B}$. abortus or $\boldsymbol{B}$. suis or only a very weak effect on $\boldsymbol{B}$. abortus with the undiluted preparation.

Table 2. The effect of using phage at routine test dilution and at $10,000 \times$ routine test dilution

\begin{tabular}{|c|c|c|c|c|c|c|c|c|c|c|}
\hline & & & & & Lysis & by phage & & & & \\
\hline & & $\mathbf{T b}$ & & 0/I & 24 & /II & 212 & $/ \mathbf{X V}$ & $371 / 2$ & XXIX \\
\hline & & $10,000 \times$ & & $10,000 \times$ & & $10,000 \times$ & & $10,000 \times$ & & $10,000 \times$ \\
\hline Strain & R.T.D. & R.T.D. & R.T.D. & R.T.D. & R.T.D. & R.T.D. & R.T.D. & R.T.D. & R.T.D. & R.T.D. \\
\hline $\begin{array}{l}\text { B. abortus 544 (FAO/ } \\
\text { WHO reference } \\
\text { strain) }\end{array}$ & C.L. & C.L. & C.L. & C.L. & C.L. & C.L. & C.L. & C.L. & C.L. & C.L. \\
\hline B. abortus S 19 & C.L. & C.L. & C.L. & C.L. & C.L. & C.L. & C L & C.L. & C.L. & C.L. \\
\hline B. abortus $61 / 1$ & C.L. & C.L. & C.L. & C.L. & C.L. & C.L. & C.L. & C.L. & C.L. & C.L. \\
\hline $\begin{array}{l}\text { B. melitensis } 16 \mathrm{M} \\
\text { (FAO/WHO reference } \\
\text { strain) }\end{array}$ & N.L. & N.L. & N.L. & N.L. & N.L. & N.L. & N.L. & N.L. & N.L. & N.L. \\
\hline B. melitensis 177 & N.L. & N.L. & N.L. & N.L. & N.L. & N L. & N.L. & N.L. & N.L. & N.L. \\
\hline $\begin{array}{l}\text { B. suis } 1330 \text { (FAO/ } \\
\text { WHO reference } \\
\text { strain) }\end{array}$ & N.L. & C.L. & N.L. & C.L. & N.L. & C.L. & N.L. & C.L. & N.L. & C.L. \\
\hline $\begin{array}{l}B \text { suis } 61 / 59 \text { (type } \mathrm{II}) \\
B . \text { suis } 61 / 178 \text { (type } \mathrm{II})\end{array}$ & N.L. & C.L. & N.L. & C.L. & N.L. & C.L. & N.L. & C.L. & N.L. & C.L. \\
\hline B. suis 61/178 (type II) & N.L. & C.L. & N.L. & C.L. & N.L. & C.L. & N.L. & C.L. & N.L. & C.L. \\
\hline
\end{tabular}

Table 3. The lytic effect of partially purified phage $\mathrm{Tb}$

\begin{tabular}{|c|c|c|c|c|}
\hline \multirow[b]{2}{*}{ Phage preparation } & \multicolumn{4}{|c|}{ Species* } \\
\hline & $\begin{array}{l}\text { B. abortus } \\
\mathbf{5 4 4}\end{array}$ & $\begin{array}{c}B . \\
\text { melitensis } \\
16 \mathrm{M}\end{array}$ & $\begin{array}{c}\text { B. suis } \\
\mathbf{1 3 3 0}\end{array}$ & $\begin{array}{l}\text { B. suis } \\
20 \text { other } \\
\text { cultures }\end{array}$ \\
\hline $\begin{array}{l}\text { undiluted stock preparation } \\
\text { pfp/ml.) }\end{array}$ & C.L. & N.L. & C.L. & C.L. \\
\hline $\begin{array}{l}\text { at routine test dilution } \\
\mathrm{pfp} / \mathrm{ml} . \text { ) }\end{array}$ & C.L. & N.L. & N.L. & N.L. \\
\hline $\begin{array}{l}\text { partially purified by } 2 \text { centri- } \\
\text { at } 100,000 g \text { for } 1 \text { hour } \\
\text { pfp/ml.) }\end{array}$ & C.L. & N.L. & C.L. & C.L. \\
\hline $\begin{array}{l}\text { partially purified R.T.D. } \\
\text { pfp/ml.) }\end{array}$ & C.L. & N.L. & N.L. & N.L. \\
\hline $\begin{array}{l}\text { nt of phage } \mathrm{Tb} \text { collected after } \\
\text { ation at } 100,000 \mathrm{~g} \text { for } 1 \mathrm{hr} \text {. }\end{array}$ & C.L. & N.L. & N.L. & - \\
\hline
\end{tabular}
centrifugation at $100,000 \mathrm{~g}$ for $\mathrm{I} \mathrm{hr}$. $\left(45 \times 10^{8} \mathrm{pfp} / \mathrm{ml}\right.$.) 
The results obtained by using phage at the two concentrations on further cultures are presented in Table 4. Cultures that were lysed by phage at R.T.D. were also lysed by phage at $10,000 \times$ R.T.D. All the cultures of Brucella suis showed lysis by phage at $10,000 \times$ R.T.D. but not at R.T.D. On the other hand, of 31 cultures of $B$. melitensis which were not lysed at R.T.D. none was lysed at 10,000 $\times$ R.T.D. These included $B$. melitensis, cultures with the biochemical and cultural characters of B. melitensis but which agglutinated in both monospecific abortus and melitensis sera as well as cultures that were biochemically $B$. melitensis but abortus serologically.

\section{Table 4. Comparison of the lytic effect of Brucella phage at} routine test dilution and at 10,000 $\times$ R.T.D.

Particulars of lysis

Lysed by phage at R.T.D. and at $10,000 \times$ R.T.D.

Lysed by phage at $10,000 \times$ R.T.D. but not lysed at R.T.D.

Not lysed by phage at either concentration
Particulars of cultures

20 cultures of $B$. abortus (type I)

30 cultures of 'British' B. melitensis includ-

ing strains from Germany, Italy and Uganda

18 cultures of $B$. abortus type III

4 cultures of $B$. abortus type III but agglu-

tinating in both monospecific sera

3 cultures biochemically $B$. abortus but serologically melitensis

1 culture biochemically $B$. melitensis but agglutinating in both monospecific sera

22 cultures of $B$. suis

13 cultures of $B$. melitensis (including WHO/ FAO reference culture $16 \mathrm{M}$ ) and others from Malta, Mexico and Germany

15 cultures of $B$. melitensis but agglutinating in both monospecific sera ( 7 from Italy and 8 from Germany)

3 cultures of $B$. melitensis biochemically but abortus serologically (1 from Germany and 2 from Italy)

Table 5. The neutralization of 5 Brucella phages by phage antiserum

\begin{tabular}{|c|c|c|}
\hline \multirow[b]{2}{*}{ Phage } & \multicolumn{2}{|c|}{$\begin{array}{l}\mathbf{K} \text { value using phage } \\
\text { antiserum produced against }\end{array}$} \\
\hline & $\begin{array}{c}\text { Tb phage } \\
\text { crude } \\
\text { preparation }\end{array}$ & $\begin{array}{c}\text { Tb phage, } \\
\text { partially } \\
\text { purified }\end{array}$ \\
\hline $\mathbf{T b}$ & 492 & 165 \\
\hline 10 & 485 & 163 \\
\hline 24 & 502 & 144 \\
\hline 212 & 640 & 157 \\
\hline 371 & 587 & 145 \\
\hline
\end{tabular}

The results of neutralization tests of the five phages by a phage antiserum produced in rabbits against crude and partially purified phage $\mathrm{Tb}$ are given in Table 5. The results clearly show that the five phages are very closely related antigenically. 


\section{DISCUSSION}

By using the conventional methods of species differentiation in the genus Brucella, most cultures can be placed into one of the three species-B. abortus, B. melitensis or $B$. suis; but over the years, an increasing number of cultures has been found which show some properties of two species, e.g. those which are $B$. abortus biochemically but $\boldsymbol{B}$. melitensis serologically; cultures which are $\boldsymbol{B}$. melitensis biochemically but $\boldsymbol{B}$. abortus serologically; cultures which are $\boldsymbol{B}$. melitensis except that they produce $\mathrm{H}_{2} \mathrm{~S}$ or require added $\mathrm{CO}_{2}$ for growth (Stableforth, 1959).

By studies of oxidative metabolism Meyer \& Cameron $(1961 a, b)$ and Meyer (1961) showed that each of the species of Brucella showed a characteristic metabolic pattern and that biotypes within the species also gave the metabolic pattern characteristic of the species. Many of the cultures used in the present paper (Brucella melitensis from Britain as well as practically all the cultures received from abroad) have been examined for their oxidative metabolic patterns (Meyer, 1962; Meyer \& Morgan, 1962). These studies showed that, without exception, all cultures with the oxidative metabolic pattern characteristic of $\boldsymbol{B}$. abortus, irrespective of their biochemical and serological properties as determined by conventional methods, were lysed by phage at R.T.D. Cultures which showed the oxidative metabolic pattern of B. melitensis, irrespective of their serological properties, were not lysed by phage at R.T.D. There is, therefore, no correlation between susceptibility to lysis by phage and serological and biochemical properties as determined by conventional methods.

By using two dilutions of phages it was possible to divide the cultures into species corresponding with oxidative metabolic patterns. The apparent lysis of Brucella suis by concentrated phage has not been reported previously; that such lysis was not due to some toxic factors present in the lysate was shown by the results obtained by partially purifying the phage by centrifugation. Replication of phage in $B$. suis has not been observed and the apparent lytic effect of $10,000 \times$ R.T.D. may be due to lysis from without. The number of cultures of $B$. suis examined was, however, small and the observations need to be extended.

From the host range tested on a large number of cultures, all five phages studied were identical. This close similarity was confirmed by neutralization tests with phage antiserum.

The author is grateful to the following for sending Brucella cultures from abroad: Mrs M. Doguer (Turkey), Dr W. Wundt (Germany), Dr O. Scheu (Germany), Dr D. Strauch (Germany), Dr M. Seeleman (Germany), Dr X. Bühlmann (Switzerland), Dr G. Gargani (Italy), Mr P. D. L. Guilbride (Uganda) and Dr H. Bendtsen (Denmark); also to various colleagues in this country who sent us cultures and to Mr C. F. Williams who was responsible for typing many of the cultures. 


\section{REFERENCES}

Adams, M. E. (1959). Bacteriophages. New York: Interscience Publ. Inc.

Fildes, P. \& KAY, D. (1955). The rate of adsorption of bacteriophage by rough and smooth strains of Salmonella typhi. Brit. J. exp. Path, 36, 534.

MEYer, M. E. (1962). Metabolic and bacteriophage identification of Brucella strains described as Brucella melitensis from cattle. Bull. Wld Hlth Org. 26, 829.

MeYer, M. E. (1961). Metabolic characterization of the genus Brucella. III. Oxidative metabolism of strains that show anomalous characteristics by conventional determinative methods. J. Bact. 82, 401.

Meyer, M. E. \& CAMERon, H. S. (1961 $a$ ). Metabolic characterization of the genus Brucella. 1. Statistical evaluation of the oxidative rates by which type 1 of each species can be identified. J. Bact. 82, 387.

Meyer, M. E. \& CAMEron, H. S. (1961 b). Metabolic characterization of the genus Brucella. II. Oxidative metabolic patterns of the described biotypes. J. Bact. 82, 396.

MeYer, M. E. \& Morgan, W. J. B. (1962). Metabolic characterization of Brucella strains that show conflicting identity by biochemical and serological methods. Bull. Wld Hlth Org. 26, 823.

Morgan, W. J. B. (1960). Comparison of various media for the growth and isolation of Brucella. Res. vet. Sci. $1,47$.

Morgan, W. J. B. (1961). The use of the thionin blue sensitivity test in the examination of Brucella. J. gen. Microbiol. 25, 135.

Morgan, W. J. B., Kay, D. \& Bradley, D. E. (1960). Brucella bacteriophage. Nature, Lond. 188, 74.

Parnas, J. (1961). Differentiation of Brucellae by the aid of phages. J. Bact. 82, 319.

REPort (1953). Joint F.A.O./W.H.O. Expert Committee on Brucellosis, Second Report F.A.O. Agricultural Studies, no. 24, 22.

Stableforth, A. W. (1959). In Infectious Diseases of Animals. Disease Due to Bacteria, 1. Ed. by A. W. Stableforth \& I. A. Galloway. London: Academic Press Inc. 